\section{Características da morbidade por causas externas em serviço de urgência}

\section{Features of Morbidity due to external causes at emergency services}

\section{Marcos Mesquita Filho'}

Maria Helena Prado de Mello Jorge ${ }^{2}$

1 Departamento de Saúde Coletiva, Faculdade de Ciências Médicas, Universidade do Vale do Sapucaí

2 Departamento de Epidemiologia, Faculdade de Saúde Pública, Universidade de São Paulo

\section{Resumo}

Objetivo: Causas externas de morbi-mortalidade são problemas relevantes de saúde pública. Dados referentes à morbidade são pouco conhecidos. Muito se perde por ausência de informações dos serviços de urgência/emergência. O objetivo deste trabalho é conhecer a situação da morbidade por causas externas em um serviço de pronto-atendimento em cidade de médio porte do sul de Minas Gerais. Métodos: Realizou-se estudo transversal e descritivo no ano de 2003, sobre 380 pacientes vitimados por causas externas encaminhados a um serviço de atendimento a urgências de Pouso Alegre, MG. Resultados: Os grupamentos mais atendidos foram: outras causas externas de traumatismos acidentais $(73,1 \%)$, destacando-se contato com objeto cortante, quedas e mordedura/golpe provocado por cães; acidentes de transportes, que corresponderam a $13,7 \%$ das vítimas; e agressões, $10,8 \%$. A prevalência em homens foi maior do que em mulheres. A maioria das vítimas tinha menos de 40 anos. O local de ocorrência mais comum foram residências, nos fins de semana, entre 12:00 e 17:59 h. Os tipos mais comuns de lesão foram ferimentos. Os traumatismos apresentaram localizações mais freqüentes nos membros superiores. Conclusões: Estes achados sugerem a existência de uma realidade, em causas externas, pouco conhecida e trabalhada pela saúde pública. A implantação de políticas de saúde e sistemas específicos de informação é alternativa para se enfrentar e conhecer melhor este problema.

Palavras-chave: Causas Externas. Lesões. Acidentes. Violências. Sistemas de Informação.

Correspondência: Marcos Mesquita Filho. Av. Cel. Alfredo Custódio de Paula 320 - Pouso Alegre, MG CEP 37550-000.E-mail: mesquita.filho@uol.com.br 
Abstract

Goals: External causes of morbidity and mortality are relevant public health problems, although this kind of data is not very well known. Much is lost due to lack of information at emergency services. This study aimed to acknowledge the status of morbidity due to external causes in an emergency unit of a medium-size city in the south of the State of Minas Gerais- Brazil. Methods: a cross-sectional, descriptive study was performed along the year of 2003 , involving 380 patients who were victims of external causes and referred to an emergency care service in Pouso Alegre, MG. Results: The groups most frequently seen were: other external causes of accidental traumas (73.1\%), especially contact with sharp objects, falls and dog bites/aggression. $13.7 \%$ of the individuals were victims of transportation accidents, and $10.8 \%$ were victims of aggression. Men presented a higher prevalence than women. Most of the victims were less than 40 years old. The site with the highest number of occurrences were households on weekends, between 12 and 5h59 p.m. The most common types of injuries were wounds. Traumas affected mostly upper limbs. Conclusions: The findings of this study may suggest that the status of external causes is very little known and approached in public health. The development of specific information systems is a possible alternative to acknowledge this kind of problem better.

Keywords: External causes. Lesions. Accidents. Violence. Information System.

\section{Introdução}

Os agravos provocados por causas externas de morbidade e mortalidade são responsáveis por expressiva parcela dos problemas de saúde. Podem ocasionar conseqüências orgânicas, psicológicas, sociais, econômicas e culturais, trazendo prejuízos consideráveis às populações afetadas. Constituem grande desafio para as políticas e serviços de saúde do Brasil, pois este setor "constitui a encruzilhada para onde confluem todos os corolários da violência" e que, "pelo número de vítimas e magnitude de seqüelas, as causas externas apresentam caráter endêmico e se converteram em problema de saúde pública" ${ }^{1}$.

Em 1998 estimou-se que 5,8 milhões de pessoas morreram em todo o mundo devido a lesões originárias de causas externas, o que correspondeu a uma taxa de 97,9 óbitos por cem mil habitantes. Destes, 3,8 milhões eram homens (128,0 por cem mil habitantes) e 1,9 milhões eram mulheres (66,7 por cem mil habitantes). As principais causas de morte a elas associada, em todo o mundo, são os acidentes de transporte e as lesões auto-infligidas ${ }^{2}$.

Gawryszewski et al. ${ }^{3}$ informam que as causas externas ocasionaram, no Brasil, uma taxa de 69,3 óbitos por cem mil habitantes no ano de 2000. Destes, $66,4 \%$ ocorreram na faixa etária dos 15 aos 44 anos de idade, sendo que a maioria das vítimas eram homens (razão entre os sexos masculino e feminino de 5,3).

As principais subcausas associadas aos óbitos por causas externas são as agressões, seguidas dos acidentes de transporte e dos eventos de natureza não-intencional $^{4}$.

Em 1996, 6,0\% das hospitalizações ocorridas no Sistema Único de Saúde (SUS) foram devidas a lesões e envenenamentos, ou seja, por causas externas. O tempo de permanência em regime de internação foi, em média, cinco dias. As lesões que provocaram o maior número de internações foram as fraturas $(37,5 \%$ dos casos $)^{5,6}$. Esta é, entretanto, apenas a pe- 
quena ponta de um iceberg, pois as características da morbidade são ainda pouco conhecidas. Em estudo efetuado a partir de indivíduos que sofreram algum tipo de lesão por acidentes de transporte e que foram atendidos em serviço de urgência e emergência ligado ao SUS em município do sul de Minas Gerais foi encontrada uma ocorrência de agravos em 592,4 acidentes por cem mil habitantes ${ }^{7}$. Entre as vítimas não-fatais de acidentes de trânsito levantadas por esta investigação houve uma proporção de 57,6\% de incapacidades autoreferidas. Em pesquisa efetuada em dois hospitais de referência para causas externas do Rio de Janeiro, nos meses de maio (Hospital I) e junho (Hospital II) do ano de 1996 foram atendidas pelo Hospital I 2.736 vítimas de causas externas (320 acidentes de trânsito) e pelo Hospital II 2.415 (290 acidentes de trânsito) ${ }^{8}$.

Em estudo sobre as causas de atendimento em pronto-socorro por acidentes e violências, em menores de 15 anos na cidade de Londrina, Paraná, observou-se que houve a predominância de quedas $(33,9 \%)$, seguida de eventos de intenção indeterminada $(31,8 \%)^{9}$. As lesões mais comumente detectadas foram traumatismos superficiais $(22,0 \%)$ e fraturas (19,5\%).

A importância das causas externas também se reflete nos gastos públicos em saúde no Brasil. Comparando-se as causas naturais e as externas constatou-se que "as últimas representaram menos de $10 \%$ do total de internações, tiveram permanência menor e gastaram cerca de $10 \%$ do valor total pago para todas as internações"10.

Esses dados vêm se mantendo em certa estabilidade e, embora o tempo de permanência dos pacientes internados por lesões decorrentes de causas externas seja menor, comparativamente às causas naturais seu custo é maior, tanto medido pelo gasto médico quanto pelo custo dia ${ }^{10}$.

Os estudos da distribuição, freqüência e possíveis determinantes dos agravos à saúde causados pelas causas externas têm grande importância para a aproximação e o reconhecimento de uma realidade de gra- ves conseqüências. Estas informações são muito importantes no desenho das políticas públicas de todas as esferas de governo. Além disso, subsidiam o planejamento das atividades de saúde em qualquer nível de complexidade. As características destes agravos entre os usuários que demandam os serviços de urgência e emergência são pouco conhecidas. O objetivo deste estudo é conhecer a situação da morbidade por causas externas em pacientes de serviço de pronto-atendimento.

\section{Métodos}

Este trabalho foi realizado com vítimas de causas externas de morbidade e mortalidade, no município de Pouso Alegre, MG, que foram atendidos entre fevereiro e junho de 2003 na Unidade de ProntoAtendimento Municipal, referência do sistema local de saúde para urgências. Este serviço é operado por equipes compostas de médicos, enfermeiros, técnicos e auxiliares, funcionando 24 horas por dia. Atende a situações que não envolvam riscos imediatos de morte ou de perda funcional. $\mathrm{Na}$ vigência de problemas desta gravidade é providenciado o encaminhamento do paciente para o Pronto-Socorro do Hospital Universitário local, referência macroregional em emergências.

Pouso Alegre situa-se na região sul do Estado de Minas Gerais, com população estimada para 2003 em 114.578 habitantes ${ }^{11}$. É um pólo industrial regional.

O estudo foi do tipo transversal e descritivo. Foram incluídos pacientes que procuraram ou foram levados a atendimento devido a ocorrências e circunstâncias ambientais que se configurassem como causas externas de morbidade e mortalidade, independentemente da gravidade das lesões, conforme a Classificação Internacional das Doenças - décima revisão ${ }^{12}$ (CID-10). Para fazer parte da amostra os indivíduos deveriam ser residentes no município de Pouso Alegre. Foram excluídas as pessoas que lá estiveram por outros motivos ou por razões não-determinadas 
e também aquelas que residissem em outras cidades. A população estudada totalizou 380 pessoas.

A coleta de dados foi efetuada através de instrumento construído e testada para ser utilizada em Sistema Municipal de Notificação de Causas Externas ${ }^{13}$. Através dele o paciente era classificado pela causa de seu atendimento, conforme o capítulo XX da CID-10 (V01-Y98), e pelo tipo e topografia do traumatismo, usando as definições do capítulo XIX (de S00 a T98). Além destas, as seguintes informações constavam do formulário:

- idade (apresentada por intervalos: menores de um ano, de um a quatro anos, cinco a nove, dez a quatorze e quinze a dezenove; daí em diante, as faixas etárias eram de dez em dez anos e por fim de oitenta e mais);

- sexo;

- local de residência da vítima;

- local da ocorrência (residência, escolas, áreas para prática de esportes, rua, estrada, áreas de comércio e serviço, áreas industriais e em construção, zona rural e outro);

- conseqüência (óbito, hospitalização, encaminhamento ou alta);

- uso de equipamentos de proteção (cinto de segurança, capacete, outros);

- uso de álcool ou drogas (auto-referido);

- hora da ocorrência (dia subdividido em quatro grupos de horário de 0h00 às 05h59; de 6 h00 às 11h59; de 12h00 às 17h59; de 18h00 às 23h59)

- dia da semana da ocorrência e do atendimento;

- tipo de atendimento recebido (orientação, prescrição, limpeza e curativo, sutura, imobilização e outro).

- localização da lesão por segmento corpóreo: cabeça (englobando cabeça e pescoço), tronco (tórax, abdome, pelve e dorso), membros superiores, membros inferiores.

A localização e descrição das lesões foram feitas pelos profissionais responsáveis pelo preenchimento do instrumento. A co- leta de dados foi efetuada por cinco enfermeiros plantonistas lotados no serviço pesquisado. Estes profissionais receberam treinamento teórico e prático para conhecimento e preenchimento da ficha. Eram distribuídos por todo o período de atendimento, perfazendo 24 horas diárias de coleta. As informações foram fornecidas pelo próprio paciente e quando o mesmo se encontrasse impossibilitado de responder, por seu acompanhante.

Foi construído banco de dados com a utilização do pacote computacional Epi Info 6.04, de domínio público. As estatísticas são apresentadas de forma descritiva, através de proporções, médias, medianas, desvio padrão e intervalos de confiança.

\section{Aspectos éticos}

O presente estudo foi aprovado pelo Comitê de Ética em Pesquisa da Faculdade de Saúde Pública da Universidade de São Paulo. Relações que pudessem estabelecer conflitos de interesse não ocorreram nesta investigação.

\section{Resultados e Discussão}

\section{Características das vítimas}

\section{Sexo}

A proporção de homens (70,8 \%) superou a de mulheres $(29,2 \%)$ numa razão de sexos (RS) igual a 2,4. Tal resultado em muito se assemelha ao encontrado em serviços de urgência/emergência do Rio de Janeiro ${ }^{8}$, onde se levantou que $69,3 \%$ dos pacientes eram de sexo masculino contra $30,7 \%$ de pacientes do sexo feminino (RS= 2,3) e também em estudo realizado posteriormente por Oliveira ${ }^{14}$ em Cuiabá $(\mathrm{RS}=2,0)$.

Conforme o tipo de causa externa a razão de sexos variou, apresentando os seguintes valores: outras causas externas, 2,1 ; acidentes de transportes, 7,7; agressões, 2,2 . Esses resultados diferem dos de Oliveira $^{14}$, que encontrou respectivamente 1,$9 ; 2,6$; e 3,5 para as mesmas causas. A pre- 
dominância masculina, no entanto, sempre está presente.

Idade

A maioria dos pacientes era menor de quarenta anos $(77,6 \%)$. Os que tinham idade inferior a vinte anos correspondiam a $41,0 \%$ da população estudada e os menores de dez anos a 24,8\%. Havia 15,6\% de indivíduos entre quarenta e cinqüenta e nove anos e $6,7 \%$ tinham mais de sessenta. A idade média foi de 26,3 anos com um desvio padrão de 19,4 anos, o que mostra uma dispersão importante entre as idades. A mediana da idade foi de 23,0 anos. Para os homens a média foi de 25,5 anos, com um desvio padrão de 16,5 e mediana de 24,0. Para as mulheres, estes valores corresponderam, respectivamente, a 28,1, 25,0 e 22,0 .

Os resultados do trabalho de Deslandes e Silva ${ }^{8}$, que encontraram uma maior concentração de vítimas de causas externas entre os vinte e trinta e nove anos, diferiram destes. Oliveira também verificou uma concentração nos estratos mais jovens da população, apresentando, entretanto, algumas diferenças quanto as faixas etárias ${ }^{14}$. Concha-Eastman e Villaceves ${ }^{15}$, discutindo a razão da maior concentração de violências e acidentes entre os jovens, colocam que a população de menor idade tem sido afetada pelo abuso ou descuido infantil, que se associa com a gravidez indesejada na adolescência, e presença de apenas um dos pais na vida destes jovens associada ao baixo nível socioeconômico. Está entre os adolescentes a população mais afetada por todo o tipo de violência. Esta não se limita apenas à agressão física, mas também inclui o abuso sexual, verbal e emocional, e o abandono. (...) As características individuais, experiências familiares, o acesso a armas, álcool, drogas, violência política e social afetam com mais freqüência este grupo de idade, principalmente aos homens. Estas condutas são aprendidas com freqüência em um ambiente familiar violento (p.6).

\section{Tipos de acidentes e de violências}

Outras causas externas de traumatismos acidentais

A Tabela 1 mostra que os eventos que mais causaram lesões na população estudada foram aqueles codificados sob a rubrica "outras causas externas de traumatismos acidentais”, com 73,1\% de freqüência. Estes resultados assemelham-se aos assinalados por Oliveira ${ }^{13}$, que constatou que essas causas acometeram 65,8\% da população que estudou.

Estes problemas acometem todas as idades, níveis socioeconômicos e tipos de ocupação. Ocorrem nas mais diversas locações, incluindo acidentes domésticos, acidentes em escolas, em locais para prática de esportes, de trabalho, de lazer. É importante notar que os acidentes de transporte $(13,7 \%)$ e as agressões $(10,8 \%)$, as mais importantes causas de mortalidade em causas externas, ocorreram em menor quantidade. Esse fato se deve, possivelmente, à grande proporção de pequenos acidentes, de menor gravidade, que acontecem principalmente no âmbito doméstico e demandam serviços de urgência.

Outras causas externas de traumatismos acidentais, dentro do capítulo das causas externas na CID-10, apresentam uma grande variedade de eventos. Nelas estão classificadas quedas nas mais diversas situações, intoxicações, problemas causados por animais, objetos cortantes, impacto acidental (objetos contundentes), entre outras. Abrangem um amplo espectro de acidentes domésticos, da esfera do trabalho, da prática de lazer e esportes, afogamentos, inalações e envenenamentos acidentais, queimaduras, etc. Entretanto, são poucos os estudos brasileiros que as abordam. Tendo em vista trabalhos de outros países ${ }^{16}$ que apontam para a relevância do tema, pode-se formular a hipótese de que a real dimensão deste problema é muito maior do que realmente se conhece e que a informação originada nos serviços de urgência é fundamental para o seu equacionamento enquanto importan- 
Tabela 1 - Vítimas por causa externa atendidas em serviço de atenção às urgências no município de Pouso Alegre, MG, fevereiro a junho de 2003.

Table 1 - Victims of external causes seen at emergency services in the city of Pouso Alegre, MG, February to June 2003.

\begin{tabular}{|c|c|c|c|}
\hline Tipo de causa externa & Número & $\% *$ & $\%$ \\
\hline Acidentes de transporte & 52 & 13,7 & 100,0 \\
\hline - Queda de bicicleta & 33 & 8,7 & 63,5 \\
\hline - Colisão de veículos & 14 & 3,7 & 26,9 \\
\hline - Atropelamento (vítima = pedestre) & 5 & 1,3 & 9,6 \\
\hline Outras causas externas de traumatismos acidentais & 278 & 73,1 & 100,0 \\
\hline - Queda & 78 & 20,5 & 28,1 \\
\hline - Exposição a forças mecânicas inanimadas & 132 & 34,7 & 47,5 \\
\hline - contato com objeto cortante(vidro, faca, ferramenta) & 82 & 21,6 & 29,5 \\
\hline - impacto acidental & 42 & 11,1 & 15,1 \\
\hline - contato com máquinas & 8 & 2,1 & 2,9 \\
\hline - Exposição a forças mecânicas animadas & 58 & 15,3 & 20,9 \\
\hline - colisão entre duas pessoas & 3 & 0,8 & 1,1 \\
\hline - mordedura ou golpe provocado por cão & 46 & 12,1 & 16,5 \\
\hline - mordedura ou golpe provocados por outros animais & 9 & 2,4 & 3,2 \\
\hline - Contato com fonte de calor & 4 & 1,1 & 1,4 \\
\hline - Outras & 6 & 1,6 & 2,2 \\
\hline Lesões autoprovocadas voluntariamente & 8 & 2,1 & 100,0 \\
\hline Agressões & 41 & 10,8 & 100,0 \\
\hline - Por meio de objeto cortante ou penetrante & 13 & 3,4 & 31,7 \\
\hline - Por meio de objeto contundente & 13 & 3,4 & 31,7 \\
\hline - Por meio de força corporal & 14 & 3,7 & 34,2 \\
\hline - Outro & 1 & 0,3 & 2,4 \\
\hline Desconhecida & 1 & 0,3 & 100,0 \\
\hline TOTAL & 380 & 100,0 & \\
\hline
\end{tabular}

*proporção de agravos em relação ao número total de ocorrências (380) / * ratio of conditions in relation to total number of occurrences (380)

te causa de morbimortalidade.

A distribuição dos 278 agravos classificados nas “outras causas externas de traumatismos acidentais” (Tabela 1) revela que $29,5 \%$ delas foram acidentes por contato com objetos cortantes (vidro, facas, tesouras, agulha, ferramentas, etc.); $28,1 \%$ por quedas; $19,7 \%$ por mordedura ou golpe provocado por animais (principalmente mordidas de cães - 16,5\%); 15,1\% acidentes por impacto acidental com objetos contundentes (pau, pedra, tijolo, etc.) e $7,6 \%$ por outras causas (contato com máquinas, colisão entre duas pessoas, queimaduras, intoxicações acidentais, contato com fonte de calor, etc.).

As lesões provocadas por objetos cortantes, quedas, objetos contundentes e contato com animais ocorreram principalmente em residências $(42,1 \%)$. Outro local de importância correspondeu ao local de trabalho (17,0\%). Essas constatações reforçam a necessidade de estudos sobre esse tema com vistas a se implantar ações de saúde para esse tipo de agravo e de adequar as intervenções sobre riscos domiciliares e ocupacionais.

A faixa etária de zero a nove anos foi a 
mais afetada neste grupo de causas com $28,8 \%$ dos casos. É um problema que repercute sobre as populações mais jovens, pois $62,6 \%$ de suas ocorrências deram-se entre menores de trinta anos. Das vítimas, $68,0 \%$ eram do sexo masculino. Os indivíduos que sofreram agravos relativos a contato ou mordida de animais apresentaram também uma razão de sexos menor: 1,5 . Verificou-se que 92,6\% destes corresponderam a acidentes com animais domésticos (85,2\% cães e $7,4 \%$ gatos).

\section{Acidentes de transporte}

Os acidentes de transporte constituíram o segundo grupo mais atendido entre as vítimas de causas externas. Os resultados desta causa diferiram pouco do estudo de Deslandes e Silva ${ }^{8}$ em dois hospitais públicos do Rio de Janeiro, que encontrou um percentual de $11,8 \%$. Apesar de ter atingido uma cifra expressiva entre os atendimentos, o número destas vítimas é ainda maior. Isso porque, algumas vezes, os acidentes de transporte causam óbitos ou podem gerar vítimas de alta gravidade. Os pacientes em piores condições procuram, em grande parte, serviços que oferecem suporte para tratamento intensivo, cirúrgico e de internação, o que não era o caso do local pesquisado.

A maioria das pessoas que sofreu algum tipo de acidente de transporte era ciclista (75,0 \%). Destes, 74,4\% foram vítimas de quedas e $25,6 \%$ de colisões.

Motociclistas e pedestres vieram a seguir com, respectivamente, 9,6\%. Já os motoristas e passageiros de automóvel, caminhonete ou caminhão foram 5,8\% destas vítimas.

Os tipos de acidentes de transporte mais registrados foram quedas de bicicleta em $63,5 \%$ das ocasiões, $26,9 \%$ de colisões e $9,6 \%$ de atropelamentos.

Estes achados são divergentes dos encontrados na literatura, tanto os referentes à mortalidade ${ }^{17,18}$ como à morbidade ${ }^{8}$, os quais informam que os acidentes de transporte mais comuns seriam os atropelamentos. As quedas predominaram prin- cipalmente porque o maior número de atendimentos, no caso dos acidentes de transporte, teve como pacientes ciclistas, pois a bicicleta é um meio de locomoção muito utilizado no município em estudo, por suas características topográficas de pouco relevo, que facilitam seu uso.

Analisando-se os acidentes de transporte por faixa etária foi observado que 91,3\% das vítimas tinham idade inferior a quarenta anos. As quedas de bicicleta aconteceram principalmente dos 10 aos 39 anos $(46,2 \%)$, enquanto as colisões entre os 15 e 39 anos (23,1\%). Metade das ocorrências em indivíduos com menos de vinte anos resultou de quedas de bicicleta

A maioria dos acidentados era do sexo masculino, RS=7,7. Esta foi muito superior a razões encontradas tanto em estudos de morbidade ${ }^{8}$ como de mortalidade ${ }^{15}$. Apenas cinco dos pacientes acidentados relataram uso de equipamento de segurança: dois motociclistas usavam capacete e dois ocupantes de veículo a motor usavam cinto de segurança.

\section{Agressões}

A terceira mais importante causa de morbidade estudada foram as agressões. Este item, correspondendo a 10,8\% dos casos, está possivelmente subnotificado. Muitas vezes, vítimas de violências domésticas, agressões sexuais e maus tratos ocultam a verdadeira causa que as fez buscar o serviço de saúde por temer represálias por parte do agressor, geralmente pessoa próxima, muitas vezes até residente sob o mesmo teto. O próprio profissional que preenche a notificação deste tipo de causa externa também pode ser intimidado por um agressor que esteja enfrentando a possibilidade de vir a ser denunciado aos serviços policiais.

Foram registrados 41 casos: $34,1 \%$ com uso de força corporal, $31,7 \%$ com objeto cortante, $31,7 \%$ com objeto contundente e $2,4 \%$ utilizando outra maneira. Entre os indivíduos agredidos, 68,3\% eram homens e $31,7 \%$ mulheres. Apenas nas idades entre 40 e 44 anos houve um número de vítimas femininas superior às masculinas. 
Destes pacientes, $63,4 \%$ tinham menos de quarenta anos de idade, sendo que $46,3 \%$ das vítimas concentraram-se entre 20 e 39 anos. Não foram notificadas agressões por arma de fogo, que apresentaram importância no estudo de Oliveira ${ }^{14}$, tendo em vista o não-atendimento, por parte deste serviço, a pacientes sob risco de morte.

\section{Outras}

"Lesões autoprovocadas" foram pouco notificadas (oito indivíduos, $2,1 \%$ ). Tal fato deve ter ocorrido por ser comum que suas vítimas ou familiares muitas vezes não desejem divulgação da ocorrência. Houve mais um paciente em outros agravos e um caso desconhecido $(0,6 \%)$.

\section{Circunstâncias das ocorrências}

\section{Região de residência}

A maioria da população estudada $(51,1 \%)$ era proveniente de localidades periféricas e de baixa renda. Pessoas que se enquadram neste perfil apresentam um risco aumentado para este tipo de agravo ${ }^{19}$. $25,8 \%$ dos casos vieram dos bairros centrais da cidade. Esse volume se justifica, pois trata-se da região muito populosa e com um acesso relativamente fácil ao pronto-atendimento.

\section{Dia da semana do evento}

A maior parte dos agravos $(47,9 \%)$ aconteceu às sextas, sábados e domingos. Os dias de menor ocorrência foram os do meio da semana (quarta e quinta-feira). Esta constatação provavelmente pode ser associada ao fato de que as pessoas, no fim de semana, ao se dedicar a atividades de lazer, muitas vezes abusam de bebidas alcoólicas e outras substâncias. Também comparecem a locais de aglomeração pública e de vias com alto fluxo de veículos, o que amplia a exposição ao risco de acidentes (principalmente de trânsito) e violências. Estes achados coincidem com os de Andrade $^{20}$, referentes ao município de Londrina, e também com os de Deslandes e Silva ${ }^{8}$. Baker et al. ${ }^{21}$ também informam que a mortalidade por homicídios e lesões não-intencionais tem incremento de sua incidência entre sexta-feira e domingo, atingindo picos nos sábados. Já Oliveira ${ }^{14}$ encontrou uma distribuição uniforme dentro dos dias da semana para Cuiabá, diferindo dos demais estudos.

Algumas das causas externas foram responsáveis por uma maior concentração dos casos no fim de semana, entre elas as agressões, nas sextas, sábados e domingos (80,5\% de suas ocorrências). Outras causas externas de traumatismos acidentais (principalmente contato com objetos cortantes e quedas) e os acidentes de transportes estiveram mais presentes aos sábados $(23,1 \%$ de suas ocorrências).

\section{Horário}

A maioria dos agravos registrados $(77,1 \%)$ aconteceu durante o dia (entre 06:00 e 17:59 hs) sendo que 52,1\% ocorreram à tarde (de meio-dia e as 17:59 horas). O período da manhã (de 06:00 às 11:59 hs) foi o segundo em número de casos. A concentração de ocorrências no período diurno deveu-se aos tipos preponderantes de causas de lesão encontradas nesta investigação. De fato, outras causas externas de traumatismos acidentais envolvem muitos acidentes domésticos e em ambiente de trabalho, que são problemas que têm uma maior probabilidade de acontecer durante o dia.

A incidência de agressões no período da tarde foi igual à da noite, e apresentou, proporcionalmente, uma maior concentração na madrugada (de 0:00 às 5:59 hs) do que as demais causas. Já os acidentes de transporte ocorreram principalmente entre 12:00 às 17:59 h. Estes resultados foram divergentes dos de Andrade (1998) ${ }^{19} \mathrm{e}$ dos de Mesquita Filho (1998) ${ }^{7}$, os quais, estudando vítimas de acidentes de transporte, encontraram uma ocorrência maior entre 18:00 e 23:59 h. As outras causas externas de traumatismo acidentais, em todas as suas classificações levantadas neste estudo, ocorreram principalmente no período entre o meio-dia e as 17:59 h. 
Os horários foram relatados pelas próprias vítimas ou por seus acompanhantes durante o preenchimento da ficha de notificação, estando, portanto, sujeitos a vieses.

Local

Os agravos ocorreram principalmente nas residências de suas vítimas (40,3\% dos problemas). Entre os eventos classificados como outras causas externas, $87,5 \%$ aconteceram em casa. Neste local também foram relatadas $43,9 \%$ das agressões. Este achado chama a atenção para a importância das moradias como pontos de desenvolvimento de ações de prevenção e controle, o que é uma nova abordagem na área das causas externas.

Os problemas estudados também aconteceram de maneira freqüente nas ruas $(26,8 \%)$. Aí foram registrados $88,5 \%$ dos acidentes de transporte, $34,1 \%$ das agressões e $15,2 \%$ das outras causas externas. Esta é situação previsível, pois os riscos inerentes às violências e acidentes fazem parte do dia-dia das ruas (trânsito problemático, crimes, infra-estrutura urbana caótica, consumo de drogas ilícitas e de bebidas alcoólicas, prostituição e exploração de crianças, entre outras).
Destacou-se também a importância do local de trabalho: $12,6 \%$ dos agravos aconteceram neste ambiente, ressaltando-se aí problemas relacionados à saúde do trabalhador e a importância do aperfeiçoamento da vigilância das lesões ocupacionais. As vítimas dos agravos nestes locais estiveram no serviço de saúde para atendimento às suas lesões, muitas vezes sem imaginar que tinham sido vitimados por um acidente de trabalho. Este fato contribui para a notificação inadequada do problema, bem como para que não se tomem medidas de proteção àqueles trabalhadores sob risco. Além disso, os agravos desta natureza não são exclusivos do ambiente de trabalho (os acidentes típicos), mas também existem os de trajeto, o que amplia as possibilidades da sua subnotificação.

Tipos de lesão e sua localização por segmento corpóreo

Foram encontradas 575 lesões nos 380 pacientes estudados (Tabela 2). A média foi de 1,5 lesões por indivíduo, com um desvio padrão de 2,2. A mediana e a moda corresponderam a uma lesão. O número mínimo de traumatismos encontrados por pessoa foi zero e o máximo foi 39. Da população estudada, $75,3 \%$ apresentaram

Tabela 2 - Número e proporção de lesões, envenenamentos e algumas outras conseqüências de causas externas em pessoas que foram atendidas em serviço de atenção às urgências no município de Pouso Alegre, MG, fevereiro a junho de 2003.

Table 2 - Number and proportion of lesions, poisonings, and other consequences of external causes in people seen in emergency services in the city of Pouso Alegre, MG, February to June 2003.

\begin{tabular}{lccccc}
\hline Tipo & \multicolumn{2}{c}{ LESÕES } & \multicolumn{2}{c}{ INDIVÍDUOS } \\
& N.o & $\%$ & N. ${ }^{\circ}$ & $\%$ \\
\hline Traumatismo superficial & 114 & 19,8 & 86 & 22,6 \\
Ferimentos & 382 & 66,4 & 276 & 72,6 \\
Fraturas & 7 & 1,2 & 7 & 1,8 \\
Luxação, entorse e distensão & 30 & 5,2 & 23 & 6,1 \\
Traumatismos dos vasos sanguíneos & 12 & 2,1 & 8 & 2,1 \\
Traumatismos dos tendões e músculos & 1 & 0,2 & 1 & 0,3 \\
Traumatismos dos órgãos internos & 5 & 0,9 & 3 & 0,8 \\
Corpo estranho & 10 & 1,7 & 10 & 2,6 \\
Queimaduras & 8 & 1,4 & 6 & 1,6 \\
Intoxicações & 5 & 0,9 & 5 & 1,3 \\
Outros e os não especificados & 1 & 0,2 & 1 & 0,3 \\
\hline
\end{tabular}


apenas uma lesão e 91,9\% tiveram entre zero e quatro. Em nove indivíduos a quantidade não foi informada.

As lesões mais registradas foram os ferimentos $(66,4 \%$,) seguidos por traumatismos superficiais (19,8\%). Em diferentes proporções (30,7\% e 16,3\%), também estas foram as principais lesões registradas em serviços semelhantes de Cuiabá ${ }^{14}$. Verificou-se que $72,6 \%$ dos 380 indivíduos atendidos eram portadores de ferimentos (média $=1,4$ por pessoa afetada). Os traumatismos superficiais somaram 114 lesões atingindo $22,6 \%$ das pessoas (1,3 lesões por vítima). Luxação, entorse, e distensão vieram a seguir com 30 ocorrências $(5,2 \%)$ atingindo 23 indivíduos $(6,1 \%)$, com uma média de 1,1. Os demais tipos de lesão acometeram $10,8 \%$ da amostra estudada, totalizando 8,6\% dos problemas notificados.

Ferimentos e traumatismos superficiais também foram predominantes em todas as faixas etárias. Nas idades entre zero e quatro anos os traumatismos de órgãos internos apresentaram uma importância relativa superior à das outras idades. $\mathrm{O}$ mesmo ocorreu com luxações, entorses e distensões entre quinze e dezenove anos. As queimaduras tiveram relativa importância abaixo dos quatro anos e acima dos sessenta. Os traumatismos de vasos sangüíneos concentraram sua ocorrência dos 35 aos 39 anos.

Em todos os tipos de traumas também houve um predomínio de pacientes de sexo masculino: $79,7 \%$ das lesões, contra $20,3 \%$ que afetaram às mulheres (razão M/ $\mathrm{F}=3,9$ ). A maior ocorrência destes agravos nos pacientes masculinos é achado comum nos mais diversos estudos. Provavelmente, as razões para esse fenômeno remontam aos aspectos culturais da sociedade brasileira, em que homens e mulheres recebem, muitas vezes, formações diferentes.

A Tabela 3 mostra relação entre os tipos de lesões e as causas externas que as ocasionaram.

Tabela 3 - Lesões segundo tipo de causa externa de morbidade e mortalidade em pacientes atendidos em serviço de atenção às urgências no município de Pouso Alegre, MG, fevereiro a junho de 2003.

Table 3 - Lesions according to the kind of external cause of morbidity and mortality in patients seen at emergency services in the city of Pouso Alegre, MG, February to June 2003.

\begin{tabular}{|c|c|c|c|c|c|c|c|c|c|c|c|c|}
\hline \multirow[t]{3}{*}{ LESÕES } & \multicolumn{12}{|c|}{ CAUSAS EXTERNAS } \\
\hline & \multicolumn{2}{|c|}{$\begin{array}{l}\text { Acidentes de } \\
\text { transporte }\end{array}$} & \multicolumn{2}{|c|}{ Agressões } & \multicolumn{2}{|c|}{$\begin{array}{c}\text { Auto- } \\
\text { provocadas }\end{array}$} & \multicolumn{2}{|c|}{$\begin{array}{c}\text { Outras causas } \\
\text { externas }\end{array}$} & \multicolumn{2}{|c|}{$\begin{array}{c}\text { Outros e } \\
\text { Indeterminados }\end{array}$} & \multicolumn{2}{|c|}{ Total } \\
\hline & N. ${ }^{\circ}$ & $\%$ & N. ${ }^{\circ}$ & $\%$ & N. ${ }^{\circ}$ & $\%$ & N. ${ }^{\circ}$ & $\%$ & N. ${ }^{\circ}$ & $\%$ & N. ${ }^{\circ}$ & $\%$ \\
\hline Traumatismo superficial & 29 & 30,5 & 15 & 22,1 & 1 & 10,0 & 69 & 17,5 & - & - & 114 & 19,8 \\
\hline Ferimento & 58 & 61,1 & 36 & 52,9 & 4 & 40,0 & 280 & 71,1 & 4 & 50,0 & 382 & 66,4 \\
\hline Luxação & 4 & 4,2 & 5 & 7,4 & - & - & 21 & 5,3 & - & - & 30 & 5,2 \\
\hline $\begin{array}{l}\text { Traumatismo de vasos } \\
\text { sangüíneos }\end{array}$ & 2 & 2,1 & 6 & 8,8 & - & - & 4 & 1,0 & - & - & 12 & 2,1 \\
\hline $\begin{array}{l}\text { Traumatismo de tendões } \\
\text { e músculos }\end{array}$ & - & - & - & - & 1 & 10,0 & - & - & - & - & 1 & 0,2 \\
\hline $\begin{array}{l}\text { Traumatismo de órgãos } \\
\text { internos }\end{array}$ & - & - & 1 & 1,5 & - & - & 2 & 0,5 & 2 & 25,0 & 5 & 0,9 \\
\hline Corpo estranho & - & - & - & - & 1 & 10,0 & 9 & 2,3 & - & - & 10 & 1,7 \\
\hline Queimadura & - & - & 4 & 5,9 & - & - & 4 & 1,0 & - & - & 8 & 1,4 \\
\hline Fratura & 2 & 2,1 & 1 & 1,5 & - & - & 4 & 1,0 & - & - & 7 & 1,2 \\
\hline Intoxicações & - & - & - & - & 3 & 30,0 & 1 & 0,3 & 1 & 12,5 & 5 & 0,9 \\
\hline Desconhecida & - & - & - & - & - & - & - & - & 1 & 12,5 & 1 & 0,2 \\
\hline Total & 95 & 100,0 & 68 & 100,0 & 10 & 100,0 & 394 & 100,0 & 8 & 100,0 & 575 & 100,0 \\
\hline
\end{tabular}


Ferimento foi o tipo de trauma prevalente nos grupamentos encontrados com maior freqüência neste estudo. Em outras causas externas de traumatismos acidentais correspondeu à maioria das lesões $(71,1 \%)$, e nos acidentes de transporte totalizaram $61,1 \%$ destas. Foi neste grupo que ocorreu a maior proporção de traumatismos superficiais (30,5\%). Dos dez agravos autoprovocados voluntariamente, quatro foram ferimentos e três foram por autointoxicações. Nas agressões, 52,9\% dos traumas corresponderam aos ferimentos.

A média de lesões por tipo de causa externa apresentou pequena variabilidade. Os acidentes de transporte tiveram 1,8 lesões por evento; as agressões, 1,7; as lesões autoprovocadas, 1,3; outras causas externas de traumatismos acidentais, 1,4 .

Os membros superiores foram atingidos por $40,0 \%$ das lesões, $28,9 \%$ delas atingiram a cabeça e $23,2 \%$ os membros inferiores. A região do tronco, que englobou tórax, abdome, pelve e dorso, proporcionalmente não sofreu tantas lesões $(7,7 \%)$. Os locais levantados no estudo de Olivei$\mathrm{ra}^{14}$ apresentaram pequenas diferenças (membros superiores $=32,8 \%$; membros inferiores $=30,5 \%$; cabeça $=26,9 \%$ e tron$\mathrm{co}=8,6 \%)$.

Os membros superiores foram o segmento onde mais se notificaram ferimentos $(46,9 \%$ destes), seguidos pela cabeça $(27,7 \%)$ e pelos membros inferiores $(19,4 \%)$. Já os traumatismos superficiais localizaram-se na cabeça $(32,5 \%)$, membros inferiores $(31,6 \%)$ e membros superiores $(24,6 \%)$.

Nos acidentes de transporte os membros superiores foram as regiões mais atingidas $(33,7 \%)$, seguidas de cabeça e pescoço $(30,4 \%)$ e membros inferiores $(26,1 \%)$.

Nas agressões e nas lesões autoprovocadas, a cabeça passa ter grande importância $(37,3 \%$ e $42,9 \%$ respectivamente), bem como os membros superiores $(34,3 \%$ e $42.9 \%$ ). Estes dois segmentos são regiões muito expostas às situações de violência: a cabeça por ser alvo visado pelo agressor e os membros superiores por serem fre- qüentemente utilizados em situações de autodefesa.

$\mathrm{O}$ grupo de causas que mais originou agravos (outras causas externas de traumatismos acidentais), por sua natureza acidental, teve uma importante concentração de agravos nos membros superiores $(43,7 \%)$, região do corpo mais utilizada nas tarefas diárias, no trabalho, nos afazeres domésticos, nas atividades de lazer e nas escolas. A cabeça e os membros inferiores tiveram proporções de ocorrência semelhantes $(24,3 \%$ e $26,9 \%$ respectivamente).

$\mathrm{Na}$ literatura brasileira praticamente não se encontram estudos sobre os tipos e a topografia das lesões provocadas por causas externas, o que dificulta a realização de comparações.

\section{Considerações finais}

As causas externas têm sido há algum tempo um desafio à saúde pública brasileira. Ações e políticas de saúde têm se mostrado insuficientes para a promoção, a prevenção, a vigilância, e para a atenção aos agravos e às suas seqüelas. A existência de informações confiáveis para a determinação das prioridades da área ainda é um desafio, principalmente quando se trata da morbidade. Os dados levantados por estudos desta natureza são importantes para que autoridades e gestores do setor da saúde e de suas interfaces desenvolvam políticas e ações para o controle e a prevenção de acidentes e de violências. A implantação de um sistema de informações, que possa trazer estes subsídios, deve ser considerada, pois é importante o reconhecimento de quem são as pessoas mais vulneráveis e as razões para tal, identificando-se as populações que vivam em situação de risco. Para tanto, as pesquisas devem abranger desde indivíduos que portem lesões mais leves até aos que vão a óbito. As ações integrais de saúde devem ser estendidas a todos, levando-se em conta que problemas sérios ocorrem com freqüência inclusive no âmbito doméstico, abordagem geralmente pouco considerada. 
A morbidade por causas externas é tema pouco trabalhado pelo setor saúde do Brasil. Lesões provocadas por elas, tais como em outras causas externas de traumatismo acidentais, não costumam ser lembradas nas propostas de políticas e ações de saúde. Nesta pesquisa foi chamada a atenção para eventos externos, como quedas acidentais, ataques efetuados por cães, acidentes com ciclistas. Esses achados (que são considerados prioridades de saúde pública para os $\mathrm{EUA}^{22}$ ) demonstram a necessidade de se conhecer melhor a extensão real do problema.

Além de diversas causas externas cuja repercussão na saúde humana é ainda pouco conhecida, os tipos de lesões por elas provocadas nem sempre são suficientemente estudados, principalmente no ní- vel ambulatorial. A produção de pesquisas nesta área é de grande importância, levando-se em conta a prioridade de se estruturar serviços que respondam pronta e efetivamente às demandas geradas por violências e acidentes, muitas vezes representadas por atendimentos emergenciais, que requerem procedimentos e tecnologias específicas prontamente disponíveis.

$\mathrm{O}$ volume de recursos financeiros consumidos pelo atendimento médico-hospitalar, além de outros custos públicos e privados, amplia ainda mais a importância das causas externas. É necessário que sejam conhecidos os seus determinantes, as circunstâncias que os envolvem, as formas de atenção aos problemas de saúde gerados e as características dos pacientes que procuram os serviços..

\section{Referências}

1. Organización Mundial de la Salud (OMS); Organización Panamericana de la Salud (OPAS). Violencia y salud. Tema 4.12 del programa provisional. In: Reunión del comité ejecutivo del consejo directivo (OPAS) y el grupo de trabajo del comité regional (OMS) 111. a, Washington, DC, CE111/19 (Esp.). Washington, DC: OPAS; 1993. p. 117.

2. Krug E. Injury: a leading cause of the global burden of disease. Geneva: World Health Organization; 1999. p 3-7.

3. Gawryzewski VP, Mello Jorge MHP, Koizumi MS. Mortes e internações dos idosos no Brasil: O desafio de integrar a saúde coletiva e a atenção individual. Rev Assoc Med Bras 2004; 50(1): 97-103

4. Brasil. Ministério da Saúde. Secretaria de Vigilância em Saúde. Departamento de Análise de Situação em Saúde. Brasil, 2005: uma análise da situação de saúde, Brasília: Ministério da Saúde; 2005.

5. Waldman EA, Mello Jorge MHP. Vigilância para acidentes e violência: instrumento para estratégias de prevenção e controle. Ciênc Saúde Coletiva 1999; 4 (1): 71-9.

6. Lebrão ML, Mello Jorge MHP, Laurenti R. Morbidade hospitalar por lesões e envenenamentos. In: Mello Jorge MHP, Laurenti R. Acidentes e violência no Brasil. Rev Saúde Pública 1997; 31(S): 26-37.

7. Mesquita Filho M. A morbidade por acidentes de trânsito em Pouso Alegre, Minas Gerais [dissertação de mestrado] . São Paulo: Universidade Federal de São Paulo; 1998.
8. Deslandes SF, Silva MFP. Análise da morbidade hospitalar por acidentes de trânsito em hospitais públicos do Rio de Janeiro, RJ, Brasil. Rev Saúde Pública 2000; 34 (4): $367-72$.

9. Martins CBG, Andrade SM. Causas externas entre menores de 15 anos em cidade do sul do Brasil: atendimentos em pronto-socorros, internações e óbitos. Rev Bras Epidemiol 2005; 8(2): 194-204.

10. Mello Jorge MHP; Koizumi MS - Gastos governamentais do SUS com internações hospitalares por causas externas: análise no Estado de São Paulo, 2000. Rev Bras Epidemiol 2004; 7(2): 228-38.

11. Brasil. Ministério da Saúde. Departamento de Informática do SUS (DATASUS). Informações de Saúde. Demográficas e Sócio-Econômicas. Censos (1980, 1991 e 2000), Contagem (1996) e projeções intercensitárias (1981 a 2007), segundo faixa etária, sexo e situação de domicílio. Disponíveis na INTERNET em www.datasus.gov.br (Acessado em 30 de maio de 2007)

12. Organização Mundial da Saúde (OMS). Classificação estatística internacional de doenças e problemas relacionados à saúde, décima revisão. 2.ed. São Paulo, EDUSP; 1995.

13. Mesquita Filho M. Vítimas de causas externas atendidas em serviço de urgência e emergência: subsídios ao desenvolvimento de sistema de informações [tese de doutorado]. São Paulo: Faculdade de Saúde Pública da Universidade de São Paulo; 2003. 
14. Oliveira LR. Subsídios para implantação de um sistema de vigilância de causas externas no município de Cuiabá/ $M T$ [tese de doutorado]. São Paulo: Faculdade de Saúde Pública da Universidade de São Paulo; 2007.

15. Concha-Eastman A, Villaveces A. Guias para el diseño, implementación y evaluación de sistemas de vigilancia epidemiológica de violencias y lesiones. Washington DC: OPAS; 2001.

16. National Center for Injury Prevention and Control (NCIPC). Home and leisure injuries in the United States: a compendium of articles from the Morbidity and Mortality Weekly Report. Atlanta: Centers for Disease Control and Prevention (CDC); 1996.

17. Mello Jorge MHP, Gawryszewski V P, Latorre, M R DI. Análise dos dados de mortalidade. In: Mello Jorge MHP, Laurenti R. Acidentes e violência no Brasil. Rev Saúde Pública 1997; 31(S): 5-25.
18. Mello Jorge MHP, Latorre MRDO. Acidentes de trânsito no Brasil: Dados e tendências. Cad Saúde Pública 1994; 10 (S1) : 19-44.

19. Minayo MCS, Souza ER. É possível prevenir a violência? Reflexões a partir do campo da saúde pública. Ciênc Saúde Coletiva 1999; 4(1): 7-23.

20. Andrade SM. Acidentes de transporte terrestre em Londrina - Paraná: análise das vítimas, dos acidentes e das fontes de informação [tese de doutorado]. São Paulo: Faculdade de Saúde Pública da Universidade de São Paulo; 1998.

21. Baker SP, O’ Neill B, Ginsburg MG, Li G. The injury fact book. $2^{\text {nd }}$ ed. New York: Oxford University Press; 1992.

22. National Center for Injury Prevention and Control (NCIPC). Injury fact book 2001-2002. Atlanta: Centers for Disease Control and Prevention (CDC); 2001.

Recebido em: 02/11/06 Versão final reapresentada em: 29/06/07

Aprovado em: 23/09/07 